\title{
SOBRE EL FUNCIONAMIENTO SEMIÓTICO DE LOS PROCEDIMIENTOS DICURSIVOS DE COHESIÓN TEXTUAL: LA PERSONA EN LA MATERIA EDUCACIÓN PARA LA CIUDADANÍA Y LOS DERECHOS HUMANOS
}

\author{
JuAn Vela Bermejo \\ Universidad de Alicante \\ Juan.Vela@ua.es
}

\begin{abstract}
Resumen
El trabajo que aquí comienza tiene como objetivo primordial el tratamiento desde una perspectiva semiótica de los mecanismos de cohesión textual mediante un conjunto de análisis discursivos circunscritos a textos del ámbito académico y, concretamente, provenientes de manuales pertenecientes a la asignatura Educación para la Ciudadanía y los Derechos Humanos. Nuestro propósito es identificar y analizar los mecanismos de cohesión textual y su interacción en el discurso, centrando el análisis en los recursos de carácter gramatical o léxico y en los procedimientos de conexión. Para ello partimos de la teoría sistémico funcional con el fin de abordar el análisis discursivo como un continuum donde entre en juego la información contextual, la organización del significado, la estructuración pragmática y la fijación lingüística del texto. Por último, este trabajo pretende reflexionar sobre el uso de los procedimientos lingüísticos de cohesión en el discurso y su función semiótica, además de la estructuración informativa que conllevan en el discurso; asimismo, mediante el tratamiento de los mecanismos cohesivos y su utilización se podrá observar cómo se construye el contexto, qué datos se aportan sobre él y cuáles son los valores o preceptos ideológicos que se pretenden transmitir, partiendo de una temática general de carácter social insertada en los contenidos de la materia Educación para la Ciudadanía.
\end{abstract}

\begin{abstract}
This paper fulfils our desire to offer a treatment of textual cohesive devices form a semiotic perspective; this work has been made through a set of discursive analysis restricted to academic texts, in particular, from manuals pertaining to the subject Educación para la Ciudadanía y los Derechos humanos. Our purpose is to identify and analyze the mechanisms of textual cohesion and its interaction in discourse; as a result, we have focused the analysis on grammar/vocabulary resources and connection procedures. Furthermore, we proceed from the Systemic Functional Linguistics in order to address the discursive analysis as a continuum where the contextual information, the meaning organization, the pragmatic structure and the final text come into play. On the one hand, this work reflects on the use of cohesion procedures on discourse and its semiotic function; on the other hand, we also treat how these mechanisms build the information structure in a determinate type of text. Also, through the treatment of cohesive devices, we will be able to observe how context is built, what data are provided on it and what the values are or ideological precepts that are intended to convey. As a conclusion, all these aspects are treated from a general social issue embedded in the contents of the subject Educación para la Ciudadanía.
\end{abstract}


PALABRAS CLAVE: Discurso, sistémico funcional, cohesión textual, contexto.
KEYWORDS: Discourse, systemic functional, textual cohesion, context.

\section{Introducción}

La teoría lingüística desarrollada por Michael Halliday, denominada en el campo disciplinar como Lingüística Sistémico Funcional (LSF), constituye una de las tradiciones más reconocidas y respetadas por los especialistas en el análisis del discurso por estudiar el lenguaje en su contexto social. Es necesario tener en cuenta que la lingüística debe analizar el funcionamiento de una lengua y su papel dentro de una cultura, de un mundo social o de situaciones particulares o específicas que fundamentan su uso. Partiendo de esta base, lo que nos interesa no es analizar "errores gramaticales" o cuestiones estilísticas, ni tampoco proponer reglas para una "correcta" utilización de la lengua, sino ofrecer una serie de resultados que evidencien las distintas herramientas que el hablante utiliza para crear y gestionar su discurso, y así ver del mismo modo cuáles eran las otras opciones de las que disponía dentro del sistema lingüístico para organizar su texto; en definitiva, en esta teoría se sustenta como idea principal las causas por las cuales el hablante/escritor ha decidido utilizar determinados recursos para construir su mensaje de acuerdo a una realidad específica, a un contexto de situación insertado en una cultura. Véanse las palabras de Eggins (2002: 40) a este aspecto:

Aunque, naturalmente, al investigador concreto le guíen intereses diferentes, o se mueva en campos de aplicación distintos, es sin embargo un factor común a todo lingüista sistemicista el interés por la manera en la que el hablante emplea el lenguaje en el transcurso de la vida social cotidiana. Este interés se apoya en cuatro principios teóricos sobre el lenguaje: que el uso del lenguaje tiene un carácter funcional; que su función es la creación de significados; que estos significados se ven influidos por el contexto social y cultural en el que se intercambian; y que el proceso del uso del lenguaje es un proceso semiótico, un proceso en el que se crean los significados eligiendo.

Pues bien, dentro de este conjunto de herramientas o recursos de los cuales se vale el interlocutor para construir significados en un contexto o realidad extraverbal, nuestro interés se ha focalizado en los procedimientos circunscritos a la denominada cohesión textual. Esta propiedad del discurso resulta de la unión entre lo semántico y lo puramente lingüístico, y engloba una serie de procedimientos léxico-gramaticales para expresar relaciones dentro del texto, configurando así su tejido interno, su organización informativa adecuada a una situación particular que lo justifica. La elección de esta propiedad textual como elemento central de análisis de los textos propuestos en este trabajo se fundamenta en que la cohesión es una condición imprescindible para la cohe- 
rencia de un discurso, y su presencia organiza el tejido lingüístico del texto y es vital para una futura comprensión e interpretación del mismo (sin olvidar otras propiedades como la coherencia o la adecuación contextual). A través del análisis detallado de los procedimientos que establecen relaciones cohesivas en un texto, podremos observar del mismo modo la realidad extralingüística que lo ha causado, la construcción de los campos semánticos y su realización con respecto a la situación particular y la cultura global y, en definitiva, la relación intrínseca que existe entre la gestación discursiva y el envoltorio contextual que motiva su creación. Consideramos que la mejor forma de observar los recursos cohesivos y su relación con la sociedad, con el contexto y, en general, con el lenguaje en la vida cotidiana, es mediante el análisis de un muestrario discursivo centrado en textos que reflejan temáticas generales de la sociedad y sus valores, siendo éste el punto de arranque de la conocida asignatura Educación para la Ciudadanía y los Derechos Humanos y el centro temático de su discurso académico visible en los diversos manuales utilizados a día de hoy en las aulas.

En el Preámbulo de la Ley Orgánica de Educación fijada en el año 2006 se observa por primera vez y desde un punto de vista ya normativo la creación de la Educación para la Ciudadanía (EpC) como la asignatura que englobará aspectos centrados en el "funcionamiento de un régimen democrático", en los "principios o derechos establecidos en la Constitución española y en los tratados o declaraciones universales de los derechos humanos" o en los "valores comunes que constituyen el sustrato de la ciudadanía democrática en un contexto global", todo con la finalidad básica de ofrecer al alumnado un "espacio de reflexión, síntesis y estudio" . Bolívar (2007) afirma que en la actualidad existe una problemática en cuanto a los objetivos fundamentales de la EpC, materia que pretende englobar la ciudadanía y el civismo como dualidad complementaria para la formación del ciudadano que convive, que se adecua a su comunidad atendiendo a una serie neutra de valores y actitudes que, en principio, deben quedar al margen de creencias ideológicas o religiosas. Pues bien, más allá de las proposiciones y abstracciones generales en las que se justifica la asignatura, concluimos que la creación de las materias de EpC ha generado una gran controversia y oposición desde su aparición, debido a una clara ambigüedad en la definición exacta de la misma, los objetivos que persigue o los medios que va a utilizar para ello. Por lo tanto, la concreción de los contenidos establecidos en esta asignatura mediante los manuales o libros texto es lo que realmente nos interesa en nuestro trabajo, ya que el análisis de sus correspon-

1 Ley orgánica 2/2006, de 3 de mayo, de Educación (BOE 106 de 4 de mayo). 
dientes discursos será un factor primordial para examinar la realidad social que se pretende transmitir, los valores ideológicos y los contenidos con los que el alumno tendrá contacto directo en su progresiva formación académica.

Consideramos oportuno aclarar una cuestión previa: nuestro artículo no consiste en analizar el marco normativo que ampara a esta asignatura, ni tampoco las razones de carácter político, moral o social que avalan la creación de la misma. Tampoco se van a abordar las cualidades pedagógicas, artísticas, estilísticas o técnicas de cada uno de los manuales tratados. Esta investigación, como ya hemos comentado con anterioridad, es de carácter lingüístico y pragmático, y mediante el análisis del discurso, partiendo del tratamiento pormenorizado de la cohesión textual, analizará un conjunto particular de textos insertados en una serie de manuales editados hasta ahora y destinados al apoyo de la enseñanza de la Educación para la Ciudadanía.

Los manuales intentan reflejar, cada uno a su manera, la normativa que los justifica, ateniéndose así a las pretensiones de las autoridades educativas. Sin embargo, cada uno de los libros es responsabilidad de los autores correspondientes y, por lo tanto, los contenidos propuestos pasan por el filtro de éstos mismos. El tratamiento de la cohesión en el análisis de los textos de Educación para la Ciudadanía propuesto en este artículo intentará poner sobre la mesa cuáles son los modos de organizar la información, de plasmar los contenidos de la materia propuesta e inculcarlos en el alumnado, configurando así los diversos contextos y realidades fuera de lo estrictamente lingüístico, con el fin de observar cómo se construye y caracteriza a la sociedad y qué valores se pretenden transmitir.

\section{Fundamentos de la Lingüística Sistémico Funcional (LSF)}

La LSF se presenta como una teoría que estudia el lenguaje desde una perspectiva tanto semiótica como social ya que concibe a éste como una herramienta para desarrollar e interpretar significados en determinados contextos sociales. Por un lado, Halliday (1985) sitúa la semiótica como punto de partida para definir el lenguaje como "uno entre otros sistemas de significado que, en su conjunto, constituyen la cultura humana". Por otro, este mismo autor circunscribe lo social a dos ámbitos: sistema social como cultura o modos de significación; conjunto de relaciones entre el lenguaje y la estructura social. Debido al carácter general de ambas concepciones, consideramos necesario fijar de una forma más específica qué importancia tiene el lenguaje dentro de esta teoría en la cual, a primera instancia, el centro donde gira todo es la posición de dicho lenguaje en contexto, dando así una especial relevancia a la vertiente pragmática o social. 
Resulta obvio que en toda cultura existen multitud de modos de expresión y significación que quedan al margen de la esfera del lenguaje como, por ejemplo, diversas manifestaciones del arte (la pintura, la música o la danza), además de otros formas de comportamiento como las modas en el vestir o las estructuras de intercambio económico y social. Es evidente que todos estos medios son formas de crear significado cultural; sin embargo, y considerando diversos niveles de relevancia o participación, el lenguaje siempre va a ocupar un papel unificador que organizará las diversas estructuras semióticas de la cultura en cuestión. Partiendo del vínculo evidente con el orden social, el lenguaje es una herramienta que ofrece un abanico de recursos tanto para crear como para comprender los significados. Por ello, el modelo sistémico funcional utiliza la metáfora de los "estratos" para explicar la importancia tanto del contexto como de los diversos tejidos que conforman el lenguaje. Hasan y Perrert (1994) fijan en dicho modelo el contexto y lo social como el escalón más importante de la estructura, es decir, el estrato superior que engloba todos los demás que, como es evidente, son la descripción del carácter interno de la lengua (semántica, léxico-gramática y fonología). En esta descripción lingüística los sistemas de significado, desarrollados mediante los de expresión y sonido, serían el puente que conectaría directamente con lo exterior, con lo social y contextual para crear así el proceso total que conlleva el lenguaje como recurso global de creación y recepción/comprensión de significados.

Es bien sabido que la doctrina funcionalista ya de por sí considera el lenguaje en su vertiente puramente comunicativa, como un recurso cuya utilidad desemboca en el correcto entendimiento de los hablantes, creando así estas funciones basadas en usos lingüísticos que fijan los "modos de hablar" o las funciones del lenguaje en una determinada comunidad. Pues bien, la LSF va más allá con respecto a la funcionalidad en el ámbito comunicativo, sobre todo con la denominada "teoría de los registros" que describe las funciones básicas del lenguaje compartidas por todos los hablantes. Hay que tener en cuenta dos cuestiones primordiales: por una parte, la "infinitud" de registros imposibles de conciliar en un inventario debido a la fluidez lingüística de las diversas comunidades; por otro, si lo social no se puede desvincular de las estructuras lingüísticas, no es posible enumerar las funciones del sistema sino hablar de "metafunciones" o propiedades generales que son inherentes a todas las lenguas. La funcionalidad del sistema se basaría en tres preceptos fundamentales: la representación de las experiencias del mundo, su plasmación a través de textos adecuados a contextos donde se crean y la interacción entre los participantes en los distintos ámbitos o situaciones en la comunidad. Halliday clasifica las siguientes metafunciones de la siguiente forma (Ghio y Fernández, 2008:24): 
1) Interpretar y representar nuestra experiencia, reduciendo la infinita variedad de los fenómenos del mundo físico y los de nuestro mundo interno o mental (los procesos de conciencia) a un número manejable de clases o tipos de fenómenos, tipos de procesos, de acontecimientos, de objetos, de instituciones, de gente, etc. (función ideativa experiencial).

2) Expresar algunas relaciones lógicas elementales como "conjunción", "disyunción", "causalidad", "condición", etc. (función ideativa lógica).

3) Expresar nuestra participación en la situación comunicativa en la que estamos involucrados: los roles que asumimos e imponemos o adjudicamos a los demás (hablante/oyente, padre/hijo, profesor/alumno, sacerdote/feligrés, compañero, amigo, etc.); nuestras actitudes, deseos, sentimientos, juicios y creencias (función interpersonal)

4) El lenguaje ofrece los recursos para que el hablante pueda realizar esas funciones en un texto organizado y cohesivo, un discurso pertinente a la situación comunicativa, es decir, un texto coherente (función textual).

Destaco del mismo modo por su carácter ilustrativo el cuadro que proponen las autoras anteriores, el cual resume este conjunto de metafunciones y las pone en relación con diversas denominaciones en otras tipologías de funciones lingüísticas.

\begin{tabular}{l|l|l|l}
\hline \multicolumn{2}{c}{ Caracterización } & \multicolumn{1}{l}{$\begin{array}{l}\text { Denominaciones } \\
\text { relacionadas con } \\
\text { esta función en } \\
\text { otras tipologías }\end{array}$} \\
\hline $\begin{array}{l}\text { Ideativa o } \\
\text { Ideacional }\end{array}$ & \multirow{2}{*}{$\begin{array}{l}\text { 1. Experiencial } \\
\text { Formación de ideas. Interpretación y } \\
\text { representación de la experiencia del } \\
\text { mundo que nos rodea y del mundo } \\
\text { interior }\end{array}$} & $\begin{array}{l}\text { Semántica } \\
\text { Representativa } \\
\text { Denotativa } \\
\text { Cognitiva }\end{array}$ \\
\cline { 2 - 4 } & 2. Lógica & $\begin{array}{l}\text { Recursos para establecer relaciones } \\
\text { lógico-gramaticales }\end{array}$ & \multicolumn{2}{|l}{} \\
\hline Textual & & $\begin{array}{l}\text { Interacción entre hablante y oyente } \\
\text { Asignación de roles de habla y } \\
\text { observaciones modal-actitudinales }\end{array}$ & $\begin{array}{l}\text { Conativa - } \\
\text { expresiva } \\
\text { (pragmática) }\end{array}$ \\
\hline & & $\begin{array}{l}\text { Organización del contenido ideativo } \\
\text { e interpersonal como texto cohesivo } \\
\text { y coherente }\end{array}$ & $\begin{array}{l}\text { Pragmática } \\
\text { discursiva } \\
\text { Perspectiva } \\
\text { funcional de } \\
\text { la oración }\end{array}$ \\
\hline
\end{tabular}


En conclusión, la organización funcional fija el proceso de interacción humana en los distintos contextos sociales, de manera que estas metafunciones se agrupan en el lenguaje y se adecuan a la situación social, propiciando un ámbito comunicativo adecuado y eficiente para el hablante y el oyente. Por lo tanto, este concepto de metafuncionalidad ordena tanto los hechos visibles en el entorno social de los hablantes que interactúan como los visibles en los estratos de la semántica y la léxico-gramática. En definitiva, el contexto, el significado y la mera expresión verbal conforman el proceso de semiosis humana y las tres viven interrelacionadas, siendo imposible olvidarse de una de ellas sin modificar el estatus del lenguaje en alguna de sus múltiples vértebras; de ahí la relevancia de los componentes funcionales descritos que conforman los diversos modos de significación patentes en el lenguaje y su empleo en los contextos sociales.

Las metafunciones del lenguaje se basan en las constantes que aparecen en las lenguas y en sus manifestaciones partiendo de la situación social, de la interacción, de la necesidad comunicativa evidente en una cultura. Además, existen tres categorías que siempre actúan en mayor o menor grado en nuestros actos comunicativos: las relaciones sociales de los participantes en el discurso, la naturaleza de este último y del proceso social y, por último, el medio por el cual se lleva a cabo esta interacción comunicativa. Estas tres categorías definen el contexto de situación donde surge el discurso-texto y, atendiendo a la teoría sistémico funcional, se han asociado a tres conceptos que conformarían la estructura semiótica de la situación: campo, tenor y modo (Halliday, 1985).

a) Campo: es el primer factor que se observa en el análisis del discurso y tiene que ver con su naturaleza más inmediata, con el tipo de acción social. Se tendrían en cuenta aspectos como los contenidos del texto y sus destinatarios, la identificación de los participantes, los hechos visibles en la situación comunicativa o las coordenadas espacio-temporales donde se ancla el texto.

b) Tenor: como el propio nombre indica, esta categoría circunscribe su campo a los participantes involucrados o afectados en la situación, destacando así sus roles discursivos, el tipo de vinculación existente entre ellos y sus actitudes o reacciones ante el hecho social que están percibiendo.

c) Modo: sería la manera o el medio mediante el cual ocurre determinado evento, en lo que concierne puramente al lenguaje. Por lo tanto, se trataría de observar el carácter oral u escrito del discurso además de otros parámetros como el canal donde se realiza el acto discursivo (en presencia o a distancia, un artículo, una carta o una conversación por teléfono).

La relación que existe entre el discurso y el contexto es inherente a la naturaleza del lenguaje en sí; de acuerdo a este hecho, puede afirmarse que estos tres factores están siempre presentes tanto en la producción de los textos como 
en la comprensión de los mismos, y es esto lo que crea el puente entre la manifestación lingüística y el contexto de situación y, si cabe, el sistema cultural.

Uno de los atractivos que posee este modelo de registro para la teoría de Halliday es la correlación con su modelo de organización del lenguaje mismo. Recordemos que la metafunción ideacional tiene que ver con la representación de la realidad que nos rodea y los recursos para construir contenidos; el significado interpersonal organiza la realidad social de las personas con las que interactuamos en determinadas situaciones particulares; por último, la metafunción abarca los recursos para dotar de relevancia y coherencia a los textos insertados en contextos específicos. Partiendo de esta base, Halliday (1978) afirma una cuestión importante: el modelo metafuncional del lenguaje puede relacionarse mediante una conexión lógica y natural con la organización del contexto, usando así el significado ideacional para construir el campo, el siginificado interpersonal para gestionar el tenor y el significado textual para describir el modo en el discurso.

El campo de un texto, al permanecer directamente relacionado con la creación de los significados experienciales, parte de la denominada transitividad gramatical; el modo está asociado con el significado textual, es decir, la organización discursiva, dotando de gran relevancia a los patrones visibles en la estructura temática e informativa del discurso; por último, el tenor se vincula a la realización de los significados interpersonales y los recursos centrados en el modo y la modalidad discursiva. A modo de recapitulación, resumimos esta teoría del registro con la siguiente tabla que reúne los patrones lingüísticos analizados con una mayor frecuencia en los textos y sus metafunciones en correlación directa con las variables registrales del contexto:

\begin{tabular}{c|c|l|l}
\hline CONTEXTO & \multicolumn{3}{|c}{ LENGUAJE } \\
\hline Variables registrales & Metafunción & \multicolumn{1}{|c}{ Léxico-Gramática } & \multicolumn{1}{|c}{ Semántica } \\
\hline Campo & Ideacional & $\begin{array}{l}\text { Transitividad } \\
\text { Relaciones lógico- } \\
\text { semánticas }\end{array}$ & $\begin{array}{l}\text { Cohesión léxica } \\
\text { Relaciones } \\
\text { conjuntivas }\end{array}$ \\
\hline Tenor & Interpersonal & $\begin{array}{l}\text { Modo y modalidad } \\
\text { Actitudes y cortesía } \\
\cdot \text { Vocación }\end{array}$ & $\begin{array}{l}\text { Estructura } \\
\text { conversacional } \\
\cdot \text { Función del habla }\end{array}$ \\
\hline Modo & Textual & $\begin{array}{l}\text { Tema } \\
\text { Estructuras } \\
\text { informativas } \\
\text { Nominalización }\end{array}$ & Referencia \\
& & Conjunción \\
\hline
\end{tabular}




\section{Alrededor de la cohesión y sus procedimientos}

Halliday (1985: 311) caracteriza la cohesión como un aspecto textual básico mediante el cual "el flujo del significado se canaliza en una corriente de discurso que puede seguirse en lugar de ser algo que se derrama sin forma alguna en cualquier dirección". Resulta evidente que la cohesión en el ámbito discursivo debe entenderse como el conjunto de relaciones que mantienen las unidades lingüísticas dentro del marco textual. Por un lado, puede definirse como una herramienta básica para la concreción lingüística, para la creación del acto comunicativo que va a iniciarse; por otro, también es el primer paso para que los posibles receptores pongan en marcha sus recursos comprensivos e interpretativos con el fin de reconstruir los significados que el hablante pretende transmitir. En definitiva, la cohesión no debe entenderse como el conjunto de reglas que organizan una lengua a nivel oracional o niveles inferiores, sino como la propiedad que engloba una gran cantidad de mecanismos de los cuales se aprovecha el lenguaje para organizar el nivel textual. Además, es evidente que no sólo los fenómenos de naturaleza lingüística determinan la creación y comprensión de un texto; es necesario tener en cuenta factores igual de relevantes como el conocimiento compartido o enciclopédico de los interlocutores, la situación particular de comunicación o incluso la gestación progresiva del texto para dotarlo de un sentido pertinente a su contexto más inmediato. Marimón (2008: 104) afirma que la cohesión debe estudiarse no a partir de un criterio estático sino dinámico, donde entren en juego otros factores de importancia similar:

Podríamos decir, pues, que la cohesión es la propiedad que hace referencia al tejido lingüístico del texto, que su presencia en un texto no garantiza que éste vaya a ser comprendido aunque, desde luego, facilita mucho el camino del receptor, y que es la totalidad del proceso de intercambio comunicativo y la puesta en juego de otras propiedades textuales -como la coherencia o la adecuación contextual- lo que finalmente dan carta de naturaleza textual-discursiva a un determinado segmento de discurso escrito o hablado.

Partiendo por un lado de esta premisa y junto a otros conceptos que siempre han estado en gran parte de las reflexiones y concepciones que se han realizado sobre la cohesión, clasificaremos las distintas relaciones cohesivas en dos grandes grupos:

a) Relaciones de cohesión basadas en la referencia y la repetición.

b) Relaciones de cohesión basadas en la conexión.

Sabemos que mediante la función referencial o representativa, el lenguaje fija su atención en el mundo real. El mantenimiento del referente es básico para la correcta interpretación del discurso por parte de los posibles receptores, 
anclando éste mismo en unas coordenadas espacio-temporales adecuadas a la realidad contextual en que se produce. Dicha fijación de la unidad referencial también se consigue mediante la recurrencia o repetición, procedimiento que no implica únicamente la repetición y reiteración de significados, sino también economizar, sustituir, emplazar o eliminar parte del contenido semántico del discurso, ganando así en eficacia tanto en la transmisión del discurso como en la interpretación del mismo. En definitiva, las relaciones cohesivas fundamentadas en la referencia y en la cohesión sirven para organizar semántica y sintácticamente un discurso, además de que su percepción por parte del destinatario puede desencadenar en los siguientes procesos: reconocimiento del enunciado como texto; fijación del mismo en unas determinadas coordenadas enunciativas; relación del discurso con la realidad extratextual; establecimiento de cadenas semánticas internas al texto que ayuden a su comprensión y a apreciar la verdadera intencionalidad o los propósitos perseguidos por el hablante.

Por otro lado, el lenguaje posee una serie de mecanismos que nos sirven para enlazar las distintas piezas que conforma un texto. Estos recursos circunscritos a una serie de unidades de conexión o conjunción no poseen únicamente la función de enlazar oraciones en el texto, sino que han ampliado su funcionamiento a un nivel discursivo, aportando significados y procesamientos de gran relevancia tanto en la construcción como en la interpretación de la unidad textual. Este hecho ha supuesto que estos elementos se conviertan del mismo modo en piezas importantes de la cohesión textual, ganando especial interés los aspectos pragmáticos y cognitivos de la comunicación en esta vertiente de análisis. A continuación, comentaremos los distintos mecanismos de los dos tipos de relaciones cohesivas básicas en el discurso (referencia/repetición y conexión), conformando así la taxonomía básica de recursos que tendremos en cuenta en nuestro análisis del corpus discursivo basado en los textos de la asignatura Educación para la ciudadanía.

\subsection{Las relaciones cohesivas basadas en la referencia y la repetición}

A la hora de establecer las diversas unidades lingüísticas que funcionen como mecanismos inherentes a la cohesión textual, hay que tener en cuenta que la gramática y el vocabulario son los dos niveles fundamentales del lenguaje donde se sostiene dicha cohesión. Por lo tanto, nuestra clasificación de este tipo de relaciones cohesivas se fundamentará en dos vertientes: por una parte, los mecanismos cohesivos que utilizan los recursos gramaticales del lenguaje (cohesión gramatical); por otra, aquellos mecanismos cohesivos que se valen de las unidades léxicas en el sistema lingüístico (cohesión léxica). Véanse las palabras de Marimón (2008: 108-109) al respecto: 
De esta manera, sea a través de la utilización de los dispositivos concretos que posee la lengua para concretarse con el contexto comunicativo, o bien mediante aquellos que permiten crear lazos intratextuales y aligerar o reiterar las cadenas significativas que se producen en el texto, cohesión léxica y cohesión gramatical conforman buena parte del tejido lingüístico que un texto debe poseer para poder ser comprendido. Las redes de relaciones que los mecanismos léxicos y gramaticales de la lengua despliegan a lo largo de un enunciado son uno de los principales objetos de estudio de la cohesión.

\section{Recursos gramaticales}

Uno de los mecanismos básicos de la cohesión gramatical y pieza central de la referencia exofórica o contextual es la deixis. Mediante el sistema deíctico el lenguaje es capaz de señalar los referentes que quedan fuera del marco intratextual en sí pero conforman su anclaje enunciativo. A través de la deixis se configuran lazos evidentes entre el discurso y su realidad extraverbal, conformando así vías necesarias para la comprensión e interpretación del texto por parte de los destinatarios. A modo ilustrativo, resumimos las distintos tipos de funciones del sistema deíctico y sus distintas clases mediante el siguiente esquema:

1) DEIXIS PERSONAL: señala el papel que desempeñan los distintos interlocutores presentes en un determinado evento comunicativo e insertados en el contexto extralingüístico.

- Índices lingüísticos: pronombres personales y posesivos, morfemas verbales de persona (marcas de primera y segunda persona).

- Ejemplos: ¿Crees en el amor a primera vista?

Yo creo que en un principio hubo una generación, de viejos toxicómanos o yonquis, que empezaron por moda ("Si yo fuera presidente", TVE 2)

2) DEIXIS ESPACIAL: a partir del aqui señalado por el hablante, el sistema deíctico fija el espacio en torno al cual se desempeña el intercambio comunicativo.

- Índices lingüísticos: adverbios y frases preposicionales con valor locativo (aquí, allí, lejos, detrás), verbos de movimiento (ir, venir, subir, acercarse) y los demostrativos (este, ese, aquel).

- Ejemplos: Compra en Dialprix, estarás más cerca del ahorro.

A río revuelto el presidente de la compañía quiere quedarse con todo lo que pueda, incluida la plata del inversionista y los sueldos del otro socio y su familia que trabajaron alli (revista Vistazo, 16/10/1997, Ecuador) 
3) DEIXIS TEMPORAL: partiendo del ahora del hablante, este tipo de deixis marca el tiempo donde se produce la enunciación.

- Índices lingüísticos: preposición y locuciones prepositivas (a partir de, antes de), adverbios y locuciones adverbiales de tiempo (ahora, ayer, mañana, la semana pasada), los demostrativos y los morfemas verbales de tiempo.

- Ejemplos: No dejes para mañana lo que puedas hacer hoy.

Yo le decía hace un rato a Pablito, perdón, a Pablo, que me hiciera el favor de darme la lista de los presos políticos que hay en Chiapas (Honorable Cámara de Senadores de México).

Para muchos autores, la anáfora es el arquetipo de relación cohesiva dentro de los mecanismos de referencia endofórica, es decir, dentro del marco textual en sí. Mederos (1988: 257) la define como "una relación entre dos segmentos textuales, uno de los cuales (término anafórico o anáforo) depende, para su interpretación, de otro segmento (antecedente), con precedencia necesaria en el orden semántico, y usual en el orden lineal". Cuando dicho orden lineal se altera, apareciendo en primer lugar el término anafórico y posteriormente el antecedente que lo identifica, hablamos del procedimiento denominado catáfora. Pues bien, estos dos recursos correferenciales se plasman en el lenguaje mediante tres recursos diferenciados:

1) PROFORMAS GRAMATICALES: unidades cuya función primaria es sustituir elementos léxicos.

- Índices lingüísticos: pronombres personales de tercera persona, pronombres relativos (quien, que, el cual, suyo), pronombres reflexivos (se, os), posesivos (su, suyo), demostrativos, cuantificadores de carácter definido o indefinido (segundo, todos, algunos), morfemas verbales de tercera persona, adverbios (así, antes, dentro), elementos deícticos con función anafórica (la víspera, al día siguiente, a continuación), cuantificadores focales (también, tampoco, al menos), el adjetivo marcador de identidad mismo o la expresión cuantificativa los demás.

- Ejemplos:

- Ella me dijo que no / la decepcioné, no lo hice nada bien (E. Bunbury).

- El profesor nos dio las directrices para el trabajo, aunque luego nadie lo hizo así.

2) EL ARTÍCULO: su función cohesiva es claramente reseñable en cuanto a la introducción de información conocida o nueva en el universo discursivo. El artículo definido el posee la función de identificador, ac- 
tuando como reconocedor del discurso. Su presencia hace referencia a una entidad ya presente en el texto, forzando que el destinatario la busque dentro o fuera del mismo para identificarlo como conocido. Por otro lado, un actúa como reconocedor de referencia, como presentador del discurso, ya que introduce un elemento nuevo que no es conocido por los interlocutores (cuando se mencione de nuevo dicho elemento se realizará mediante el artículo el).

- Ejemplo: La primera rebaja de salarios de funcionarios y congelación de las pensiones se saldará, de momento, con una huelga de empleados públicos el próximo 2 de junio. Aunque los sindicatos no descartan recurrir a su arma más drástica: la huelga general (El País, 13/5/2010)

3) LA DEIXIS TEXTUAL O DISCURSIVA: situamos este tipo de deixis fuera del sistema deíctico prototípico ya que su ámbito funcional se circunscribe al marco textual. Su función puede ser anafórica o catafórica y mediante su uso el hablante puede referirse al propio discurso, convirtiéndose éste en la referencia básica. La deixis textual suele aparecer con marcas casi estandarizadas, normalmente unidades con valor deícitico temporal o espacial (antes, después, más abajo, a continuación).

- Ejemplo: En las páginas de Opinión de "La Vanguardia" del sábado 28 de octubre, Manuel Trallero escribe un atropellado y agrio artículo que, de acuerdo con el título, "Contra 'Ubú president", tendría que ir contra esa obra que se representa en el teatro Tívoli de Barcelona. Pues no, no va contra la obra, aunque aproveche la ocasión para descalificarla, probablemente sin haberla visto. El señor Trallero arremete contra los espectadores que han ido, que van o vayan a verla, "refugiados, según él, en el anonimato de una masa, en el silencio cómplice de la oscuridad de un patio de butacas"..., y añade un poco más abajo que en la actitud del público "hay algo de fascismo soterrado" ( La Vanguardia, 2/11/1995)

\section{Recursos léxicos}

Cuando el tejido de relaciones entre las unidades lingüísticas se da entre elementos con significado léxico, nos encontramos con una cohesión léxica cuya función básica es la contigüidad de significado a lo largo del discurso (de ahí que podamos hablar de mecanismos de recurrencia o repetición).

En primer lugar, este tipo de cohesión puede sostenerse en un discurso mediante la repetición de un mismo lexema de una forma total (lexemas idénticos) o parcial (transcategorizaciones denominales o deverbales). Dicha repetición puede obedecer a una intencionalidad directa del hablante (el cual 
pretende reincidir en una idea exacta) o, del mismo modo, a una falta de vocabulario evidente.

Curiosamente ahora, de vuelta en la hacienda, habiendo estado ausente de ésta sólo tres meses, le parecía haber llegado a su verdadera casa, a su casa casa, donde era dueña de sus espacios (González E., Quién como Dios, 1999)

[...] en la vida hay millones de cosas, el amor, la amistad, la honestidad, una flor, una página de un libro, unos autobuses que pasan, una lluvia que no llega, un poco de sol, un café, una ilusión, vivir. Porque vivir, a secas, por nosotros y entre nosotros, es cojonudo ("Si yo fuera presidente", 18/10/83, TVE2)

En segundo lugar, varios son los procedimientos que pueden comentarse cuando lo que se pretende es la reiteración de un mismo significado:

1) SINONIMIA: se habla de términos sinónimos cuando existe una equivalencia referencial en los significados que transmiten. Sin embargo, las relaciones sinonímicas normalmente son de carácter incompleto, siendo estos cuasi sinónimos los más frecuentes en el ámbito discursivo. También cabría destacar que el proceso sinonímico, más allá de las relaciones de sentido, también obedece al factor contextual, en la medida en que puede existir relación de contigüidad semántica entre elementos de distintos niveles de la lengua. Lyons (1997:87) afirma que este tipo de relación no se da sólo entre lexemas sino también entre expresiones tanto simples como complejas; además, el criterio básico sería la identidad y no meramente la semejanza. En definitiva, la función cohesiva fundamental de este recurso descansa en reiterar un mismo significado introduciendo matizaciones estilísticas que evidencien la intencionalidad del hablante (eliminando del mismo modo una posible redundancia en el discurso)

- Ejemplos:

- También que nos cuidemos y que nos fijemos en gente que está mejor que nosotros, siempre y cuando sirva como aliciente y como motivación, no como frustración ("A tu Salud", en La Razón digital, 2004).

- Aunque le amenazó con suspenderle, su advertencia no le amedrentó para nada.

2) ANTONIMIA: en este proceso encontramos relaciones de oposición entre varios términos. Pueden aparecer antónimos donde se admita una gradación (grande/pequeño), unidades complementarias entre las cuales no exista otra posibilidad (hombre/mujer) o términos inversos que se implican de una forma mutua (tío/sobrino). Su función cohesiva es evidente ya que obliga al destinatario a realizar el recorrido anafórico a lo largo del discurso para recuperar el significado antónimo o contrario. 
- Ejemplos:

- De allí que el debate no se planteara en términos de la antinomia mujerhombre, sino en el de cómo se pueden manejar los medios (Knecker, L.S., Formas de organización de las mujeres en Argentina, 1993)

- ¿La leche está fría o caliente para tu gusto?

3) HIPERONIMIA-HIPONIMIA: en este tipo de relación paradigmática encontramos términos específicos, los hipónimos, que se agrupan dentro de un concepto más general, el hiperónimo.

- Ejemplos:

- La vida de una pequeña y tranquila ciudad de Estados Unidos se ve inesperadamente alterada por el ataque de las más diversas clases de aves, desde pequeños gorriones hasta cuervos y gaviotas que parecen haberse unido contra la humanidad (anónimo, página web, 1999).

- Los roles principales son los dos esposos vinculados mediante la institución matrimonial, pero existe también el rol del hijo, el del hermano y multitud de roles menores (abuelo, suegro, yerno, tío, sobrino, etc.) perfectamente definidos (Lucas, A., Introducción a la sociología, 1996).

4) PROFORMAS LÉXICAS: en relación directa con el caso anterior, un ejemplo claro de hiperonimia discursiva sería el uso de las denominadas proformas léxicas, unidades lingüísticas de significado muy amplio con una finalidad claramente generalizadora. Este conjunto de unidades puede ser nominal o verbal: persona, cosa, hecho, hacer, tener, ser...

- Ejemplo: En consecuencia, resulta claramente conveniente que el consumidor tenga plena información acerca de lo que le va a costar el hecho de entrar en morosidad. Entre otras cosas, ello induce a la persona a preocuparse de ser puntual y cuidadosa en sus pagos (Senado de Chile, 1986).

Mederos (1988:260) describe el funcionamiento de la elipsis cohesiva como "la ausencia de una pieza necesaria para la completud estructural de la construcción, recuperable en el contexto verbal o a partir de información proveniente del no verbal". Puede ser de tipo norminal, comparativo o verbal, y su función cohesiva se basa en eliminar una posible redundancia o repetición de elementos, evitando así la información anunciada en varias ocasiones o demasiado conocida e insertando fácilmente información nueva sin un gran soporte temático previo.

- ¿No conduces? No (conduzco) porque no tengo carnet (de conducir). 
- Sabes que lo digo de verdad / (sabes) que no voy a fallarte en nada / (sabes) que tengo mucha fuerza de voluntad / (sabes) que no te fallaré en nada (Los Piratas).

Dentro de la cohesión léxica, es necesario tener en cuenta que las relaciones de contigüidad de significados que conforman el tejido semántico de un texto no siempre provienen de la presencia de rasgos estructurales comunes entre las unidades lingüísticas; es en este caso cuando entran en juego las relaciones pragmáticas: la subjetividad del hablante, su intención, su capacidad connotativa a la hora de utilizar el lenguaje. En este caso, el mantenimiento del referente descansará tanto en el contexto extraverbal como en el conocimiento compartido o enciclopédico de los interlocutores. Veamos algunos casos:

- Los hablantes pueden realizar el recorrido anafórico de determinados conceptos en un discurso debido al conocimiento compartido que poseen, el cual puede ser previo al propio intercambio comunicativo, produciéndose una denominada anáfora pragmática. En muchas ocasiones, nuestro conocimiento enciclopédico supone la creación de marcos o guiones mentales, con la posibilidad de que los interlocutores puedan construir las expectativas discursivas a lo largo de la interpretación de un discurso si leen o escuchan un término determinado que les despierte un posible recorrido anafórico propio. Nos decantamos por el concepto colocación léxica, definida por Ghio y Fernández (2008: 232) como la "relación no-estructural entre elementos léxicos, medidos por la posibilidad de su co-ocurrencia en el texto"

Ejemplos: En África la pobreza ha crecido considerablemente durante los últimos veinticinco años. [...] Esta precariedad económica tiene amplios efectos en las condiciones de vida y en la estabilidad social y política ( $E l$ Mundo, 7/7/2006).

Miami es una seductora ciudad al sur de Florida, el Estado del Sol. Con preciosas playas, una vida nocturna sin igual y un perfecto clima no es ninguna sorpresa que sea el lugar más elegido por los ricos y famosos para vivir. Al final de un día de cursos de inglés disfruta dando un paseo por un largo sendero de palmeras y a lo mejor verás cómo filman una película (Agencia EF, www.ef.com).

- La metáfora y la metonimia son recursos activados normalmente por los hablantes para satisfacer su necesidad de encontrar soluciones expresivas para un concepto. En muchísimas ocasiones, su uso está tan lexicalizado que no se aprecia la relación tropológica que se está realizando en su 
utilización. Por un lado, las metáforas conceptuales poseen valor cohesivo en la medida en que el texto funciona como dominio de destino sobre el cual se superponen determinados conceptos de otro dominio origen; en este caso, no hablamos de una imagen aislada, sino de un dominio cognitivo común donde la relación palpable entre diversos conceptos fija su sentido en el texto. Por otro lado, las metonimias se basan del mismo modo en una relación de contigüidad, estableciendo en este caso referencias parciales de una entidad. El siguiente cuadro resume las principales metáforas y metonimias conceptuales según Cuenca y Hilferty (1999: 100, 112).

\begin{tabular}{l|l}
\hline METAFORAS & METONIMIAS \\
\hline MORIR ES PARTIR & EL TODO POR LA PARTE \\
LAS PERSONAS SON ANIMALES & LA PARTE POR EL TODO \\
LAS TAREAS DIFÍCILES SON & EL CONTENIDO POR EL \\
CARGAS & CONTINENTE \\
LAS TEORÍAS SON EDIFICIOS & LA PERSONA POR SU NOMBRE \\
LA VIDA ES UN VIAJE & EL LUGAR POR EL \\
EL TIEMPO ES UN OBJETO DE & ACONTECIMIENTO \\
VALOR & LA INSTITUCIÓN POR LAS \\
LAS IDEAS SON ALIMENTOS & PERSONAS RESPONSABLES \\
EL AMOR ES UNA GUERRA & EL PRODUCTOR POR EL \\
& PRODUCTO \\
& EL CONTROLADOR POR LOS \\
& SUBORDINADOS \\
& EL LUGAR FÍSICO POR LA \\
& INSTITUCIÓN SITUADA EN \\
\hline
\end{tabular}

- Ejemplos:

- METÁFORA: Tengo un amigo del que me enamoré... Demasiado. [...] ¿Lucho por él? ¿Lucho por nuestra relación? ¿Lucho por el amor o me quedo con las ganas? (Yahoo Respuestas, México)

- METONIMIA: Movistar reacciona ante las acusaciones de estar especulando con sus servicios de telefonía móvil (Telesemana.com, 12/05/2010). 


\subsection{Las relaciones cohesivas basadas en la conexión}

En esta vertiente de la cohesión nos encontramos con una serie de unidades cuyo cometido no es de tipo referencial sino de organización de la materia textual. La atención a estas unidades, denominadas marcadores del discurso, ha ganado en relevancia con el desarrollo de la pragmática, la lingüística cognitiva o las disciplinas que se encargan del análisis del discurso. Estos marcadores no poseen un valor sintáctico dentro de la oración pero guían inferencialmente el proceso de comprensión e interpretación gracias a sus propiedades morfosintácticas, semánticas y pragmáticas. Esta ayuda en el procesamiento discursivo gracias a este tipo de unidades puede darse atendiendo a dos vertientes: una puramente argumentativa, donde se enlazan nuevas continuaciones del discurso o se cierran otras; otra esencialmente informativa, donde se enfatizan los tópicos del discurso o los argumentos de especial relevancia. Adjuntamos a continuación la clasificación que proponen Martín Zorraquino y Portolés (1999) de los marcadores atendiendo a la función discursiva que ejercen en el marco textual:

\section{1) ESTRUCTURADORES DE LA INFORMACIÓN}

$\rightarrow$ Organizan el contenido informativo del discurso.

- Comentadores: pues, pues bien, así las cosas;

- Ordenadores: en primer/segundo lugar, por una/otra parte;

- Digresores: por cierto, a propósito, a todo esto.

2) CONECTORES

$\rightarrow$ Vinculan semántica y pragmáticamente los miembros visibles en el discurso.

- Aditivos: además, encima, aparte, incluso;

- Consecutivos: por tanto, por consiguiente, de ahí, en consecuencia;

- Contraargumentativos: en cambio, por el contrario, antes bien.

3) REFORMULADORES

$\rightarrow$ Corrigen o presentan de una forma más correcta un miembro del discurso en comparación a una formulación previa del mismo referente.

- Explicativos: o sea, es decir, esto es, a saber;

- De rectificación: mejor dicho, mejor aún, más bien;

- De distanciamiento: en cualquier caso, de todos modos, en todo caso;

- Recapitulativos: en suma, en fin, al fin y al cabo, en definitiva.

4) OPERADORES ARGUMENTATIVOS

$\rightarrow$ Establecen las posibilidades argumentativas de los miembros que introducen en el texto.

- De refuerzo argumentativo: en realidad, de hecho, en el fondo;

- De concreción: por ejemplo, en particular. 


\section{5) MARCADORES CONVERSACIONALES}

$\rightarrow$ Partículas discursivas de mayor frecuencia en la vertiente oral.

- De modalidad epistémica: desde luego, claro;

- De modalidad deóntica: bien, bueno, vale, así;

- Enfocadores de alteridad: mira, hombre, oye;

- Metadiscursivos conversacionales: bueno, eh, este.

\section{Ejemplos}

- Estructurador de la información (comentador): La placa reza: "Carrer de les Jonqueres"; pues bien, tendría que decir "de Jonqueres", porque evoca el nombre del convento allí sito, que no un juncal. (La Vanguardia, 02/01/1995).

- Conector contraargumentativo: En estos momentos el caso no ha terminado, antes bien continúa pendiente de la sentencia que ha de dictar la sección sexta de la Audiencia de Barcelona, una sentencia que en cualquier circunstancia respetaremos. (La Vanguardia, 02/12/1995).

- Reformulador de rectificación: George Foreman había nacido en Marshall, estado de Texas, en 1949. Texas se acepta como tierra de gente rica, de señoras estupendas y tipos como J. R. Pero las oportunidades para un negro sin instrucción son muy pocas o, mejor dicho, ninguna. (La Vanguardia, 22/11/1994).

- Operador de refuerzo argumentativo: Luego de la caída del Muro de Berlín en 1989, el neoliberalismo ha podido extenderse por el mundo como mancha de aceite. Y en el fondo lo que se libra es hasta más una batalla cultural que política. (El País, 04/10/2001, Uruguay).

- Marcador conversacional enfocador de alteridad: Bien Mágico, usted es un personaje realmente singular, yo no sé si son las buenas o las malas lenguas las que le clasifican de esa manera, pero por ejemplo a usted no le interesa el dinero. Sí, claro que sí. ¿Le interesa? Sí. Pero, hombre, si me han dicho que usted no ha cobrado o se fue de vacaciones sin cobrar todavía cosas de la temporada pasada en su club, y eso en un futbolista, ni en nadie, es normal. ("Un día es un día", 05/07/90, TVE 1).

\section{4. "La persona": metodología, corpus y análisis discursivos}

El conjunto textual utilizado para nuestro trabajo consta de tres discursos extraídos de diferentes manuales de Educación para la ciudadanía y los derechos humanos utilizados en la actualidad en las aulas. Ante la proliferación de libros de texto adscritos a esta materia, hemos circunscrito la selección de los discursos al ámbito de la secundaria obligatoria, en concreto el tercer curso que es el espacio académico iniciador de esta asignatura. Para el análisis de los diferentes discursos se ha considerado oportuno seguir una línea temática común 
en la selección de estos textos, con el fin de apreciar de nuestros diversos análisis los fenómenos cohesivos más interesantes y así poder ponerlos en relación entre los distintos manuales, observando así los tejidos semánticos y su relación con el contexto y la intencionalidad de los autores. La temática fundamental del conjunto de textos sería "la persona", englobando así al individuo, su componente afectivo y su entorno. A continuación señalo la lista bibliográfica de los manuales utilizados en este artículo:

- Texto 1: PÉREZ, J.; DÍAZ, C.; DÍAZ, J. (2007): Jóvenes ciudadan@s. Educación para la ciudadanía y los derechos humanos. Madrid: Pearson-Alhambra.

- Texto 2: AgUilar, T.; CABAllero, A.; DAUSÀ, N.; MESTRE, J.; VILASECA, S. (2007): Educación para la ciudadanía y los derechos humanos (ESO). Barcelona: Grupo Edebé.

- Texto 3: GONZÁLEZ, F. (2007): Educación para la Ciudadanía y los Derechos Humanos. Proyecto más que uno. Madrid: Edelvives.

El modelo de análisis del discurso configurado para este trabajo se ha fundamentado en dos partes sistemáticas: por un lado, la macroestructura del discurso; por otro, la cohesión textual. Resulta evidente que cualquier texto debe poseer un contenido informativo intencionalmente decidido y organizado por el hablante que desea comunicar un hecho concreto. Siguiendo la estela de Van Dijk (1978), el primer escalón dentro de los análisis de textos propuestos va a recaer en la macroestructura del discurso, es decir, su esqueleto significativo o su conjunto de conexiones semánticas que configuran al texto como un todo. Cualquier discurso posee una macroestructura, una organización informativa identificable que parte de un tópico general, una proposición que domina la información semántica del discurso y ordena jerárquicamente su estructuración conceptual. A partir de ahí, el texto en sí podrá dividirse en dos niveles relacionados: las microproposiciones $(\mathrm{mp})$ que forman una unidad de contenido; las macroproposiciones (MP) como unidades jerárquicamente mayores que se fundamentan por el contenido de las microproposiciones. Aunque nuestro artículo se fundamente en el análisis de la cohesión como propiedad discursiva básica en el corpus de textos seleccionado, consideramos vital establecer en primer lugar la estructura informativa de los discursos como punto de arranque para el análisis posterior. La cohesión tiene que ver con la concreción lingüística de una idea, un hecho, un acontecimiento o una situación y, del mismo modo, es el eje fundamental para tejer las conexiones semánticas y pragmáticas que se van a dar en ese futuro texto; por lo tanto, es imprescindible tener en cuenta cuál es la organización que se ha configurado en el discurso, con el fin de ponerla en relación directa con los recursos cohesivos utilizados y que han ayudado a fijar ese esqueleto significativo, consiguiendo 
así un modelo de análisis completo en el cual se evidencie la relación necesaria entre cohesión textual y coherencia semántica.

El tratamiento de la cohesión textual conforma la parte fundamental del análisis discursivo en el que, como hemos comentado en anteriores ocasiones, prestamos una atención completa a los mecanismos de cohesión textual y su conexión con las redes semánticas fundamentales en estos textos vinculados a la materia de Educación para la Ciudadanía. El análisis de los textos seleccionados en el corpus propuesto se ha fundamentado en el tratamiento pormenorizado de los mecanismos cohesivos que sobresalen en cada discurso, y su puesta en relación directa con el tejido semántico e informativo del mismo. A través de esta idea general se ha conseguido catalogar una serie amplia y rica de fenómenos centrados en la cohesión textual, incluyendo del mismo modo una descripción de cómo interactúan tanto en el marco textual en sí como evidenciando cuestiones de carácter pragmático o semántico tales como la intencionalidad del autor, las perspectivas ideológicas o subjetivas o la construcción del contexto de situación donde se inserta el discurso.

Texto 1

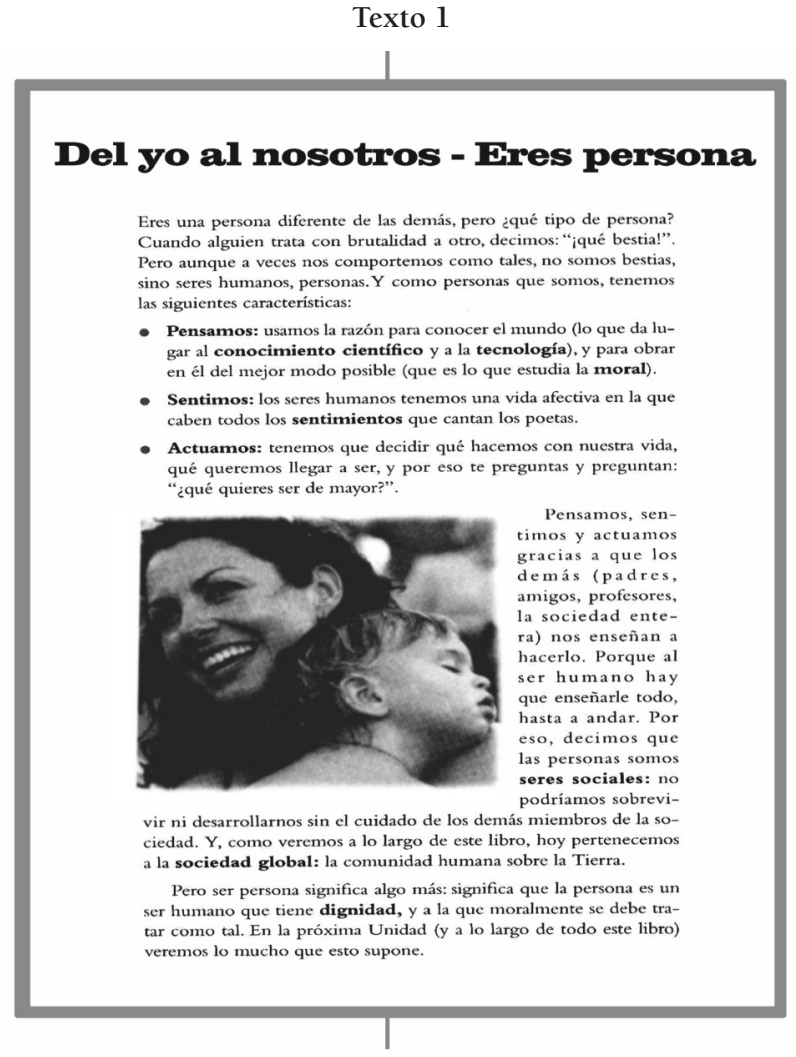




\section{TÓPICO: La persona}

MP1: Las personas se diferencian de los seres humanos por tener características propias.

mpl: Piensan para conocer el mundo que les rodea y actuar en él.

mp2: Tienen vida afectiva y sentimientos.

mp3: Actúan para lograr objetivos en su vida.

MP2: El ser humano necesita un proceso de enseñanza.

mp4: La persona piensa, siente y actúa gracias a la enseñanza ejercida por otros miembros.

mp5: La persona es un ser social.

mp6: El ser humano pertenece a una sociedad global.

mp7: La persona posee dignidad.

El aparato deíctico conforma uno de los aspectos más reseñables de este texto. Ya desde la primera línea apreciamos la distinción clara TÚ-EL RESTO (eres, los demás) que da pie al eje vertebrador del discurso: NOSOTROS SOMOS PERSONAS. De ahí surge el gran surtido de formas englobadas en la deixis personal, contabilizándose más de veinticinco elementos indicadores de la primera persona del plural, del nosotros convertido en morfemas verbales (somos, sentimos, tenemos), pronombres posesivos (nuestra) o personales (desarrollarnos). El eje tú/yo correspondería a un mismo hecho: la segunda persona visible en el texto, aunque pretende ser una apelación directa al joven lector, también responde y se inmiscuye en el "yo", en el "nosotros" global (eres una persona diferente de las demás; por eso te preguntas). También aparece una tercera persona extraverbal con valor deíctico, referida básicamente a otros miembros generales de la comunidad, a entes que interactúan con el "yo" del texto. Se representan con morfemas verbales o proformas con gran valor cohesivo como pronombres indefinidos: cuando alguien trata con brutalidad a otro; por eso te preguntas y preguntan.

La deixis temporal queda anclada en el texto mediante dos procedimientos; por un lado, se observa el continuo uso del presente de indicativo en las diversas formas verbales; por otro, el adverbio hoy fija las coordenadas temporales partiendo del "ahora" del interlocutor. El tiempo de la enunciación queda marcado por el hecho de que, en la actualidad, los seres humanos pertenecen a una comunidad global. También cabría añadir dos casos de deixis textual donde el autor refleja posteriores contenidos que se van a tratar durante el desarrollo del manual (además, emplea grados de proximidad tanto en el espacio como en el intervalo de tiempo con el demostrativo este, el adjetivo próxima o las formas verbales en futuro de indicativo: $y$, como veremos a lo largo de este libro; en la próxima unidad (y a lo largo de todo este libro). 
Los casos de referencia endofórica dentro del texto se resumen en varios empleos de términos anafóricos a través de pronombres, clíticos personales o elementos de carácter neutro: pensamos, sentimos [...] nos enseñan a hacerlo; porque al ser humano hay que enseñarle; en la próxima unidad veremos lo que esto supone. La catáfora también se hace visible con el uso de proformas léxicas como los demás o algo más: gracias a que los demás (padres, amigos, profesores, la sociedad entera); pero ser persona significa algo más: significa que la persona es un...

Tras la observación de los elementos gramaticales que dotan de cohesión al texto analizado, es necesario tener en cuenta el conjunto de redes semánticas que se tejen a través de los procedimientos de cohesión léxica. Sabemos, por un lado, que el tópico del discurso es considerar al conjunto de individuos que puebla el planeta como humanos, como personas capaces de actuar de acuerdo a una sociedad establecida. De ahí que uno de los aspectos más relevantes sea una cohesión basada en la repetición del mismo lexema, donde contabilizamos el uso del vocablo persona en siete ocasiones y la locución nominal ser humano en cuatro. Tanta recurrencia supone una fijación obvia del autor en repetir la idea exacta anteriormente comentada, aunque parece que también tiene que ver su inexpresividad o incapacidad de utilizar otros términos, visible ya de por sí a lo largo de un discurso que brilla por su neutralidad y sencillez (esta intencionalidad quizá pueda relacionarse con el público al cual va dirigido el texto, de corta edad o adolescente). Cabe destacar casos de repetición exacta como refuerzo argumentativo en estructuras casi paralelísticas: ser persona significa algo más: significa que la persona es un ser humano...

Los elementos sinonímicos conforman una red semántica basada en la condición global del individuo: persona, ser humano, ser social, miembro de la sociedad. Nos encontramos con reformulaciones de un mismo hecho: hoy pertenecemos a la sociedad global: la comunidad humana sobre la Tierra. Además, el discurso se inicia con un proceso antonímico que reincide en la misma idea o tópico, las personas no son animales: pero aunque a veces nos comportamos como tales, no somos bestias, sino seres humanos, personas. También podría establecerse una red hiperonímica basada en los rasgos propios del ser humano: sentimientos, razón, vida afectiva, conocimiento científico, dignidad. Finalmente, el uso de la elipsis (sobre todo de carácter verbal) descarga de redundancia expresiva en muchas ocasiones al texto: eres una persona diferente de las demás, pero ¿qué tipo de persona $(\varnothing)$ ?; además, también es apreciable la sustitución general mediante locuciones del tipo "como tal", incluso con cierto valor catafórico: pero aunque a veces nos comportemos como tales, no somos bestias.

Expresiones como "todos los sentimientos que cantan los poetas" o "iqué quieres ser de mayor?" juegan con el conocimiento compartido de los hablantes, y su colocación en el texto ejerce un gran papel cohesivo en la medida en 
que crea las inferencias o expectativas en los receptores para un correcto seguimiento del texto y una adecuada compresión de éste. Del mismo modo, y para favorecer la progresión comunicativa, aparecen (aunque no en una gran medida) marcadores del discurso sobre todo de carácter conector: porque al ser humano hay que enseñarle todo, hasta a andar. Por eso, decimos... (causativo); Pero ser persona significa algo más (digresor).

A modo de conclusión, el esquema semántico que hay detrás del texto o, mejor dicho, la intencionalidad del autor en su contexto pertinente se basa en la reincidencia exacerbada del "yo", del "nosotros" como individuos racionales constituyentes de una sociedad. Para ello, fundamenta su discurso en cinco ideas fijas, en casi cinco metáforas conceptuales que guían inferencialmente tanto al escritor en su redacción como al receptor en su lectura.

\author{
LA PERSONA (NO) ES UNA BESTIA \\ $\downarrow$ \\ LA PERSONA ES UN SER HUMANO \\ $\downarrow$ \\ LA PERSONA ES UN SER SOCIAL \\ $\downarrow$ \\ LA PERSONA ES UN SER DIGNO \\ $\downarrow$ \\ LA SOCIEDAD ES UNA COMUNIDAD HUMANA
}

Texto 2

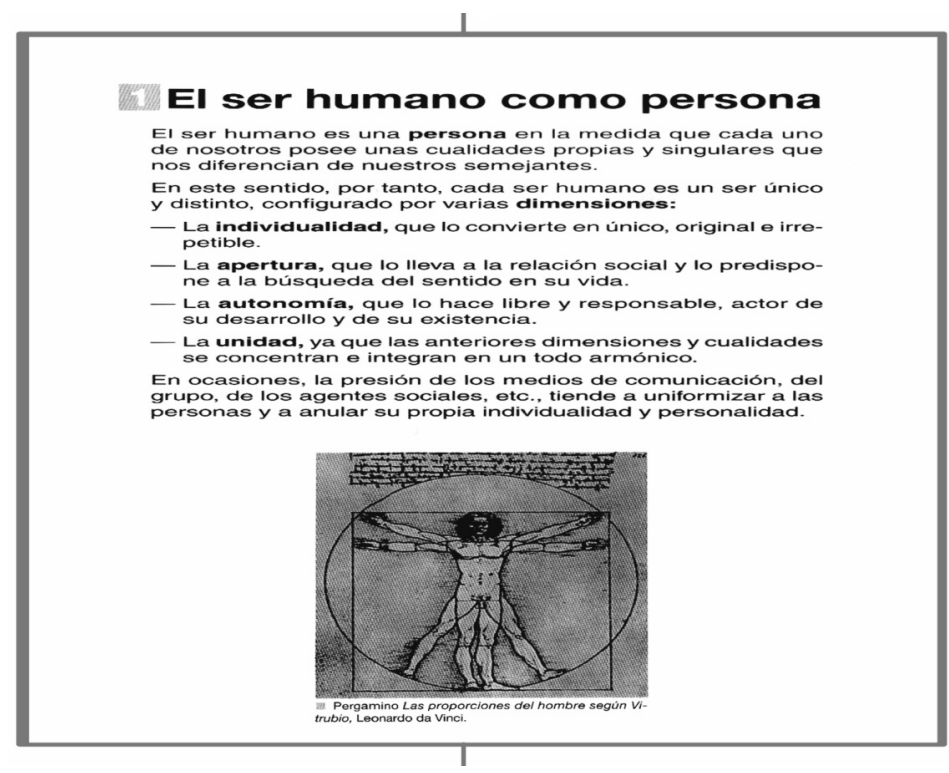


TÓPICO: Las cualidades del ser humano.

MP1: El ser humano es una persona con cualidades propias y singulares.

MP2: El ser humano está configurado por varias dimensiones.

mpl: La individualidad.

mp2: La apertura.

mp3: La autonomía

mp4: La unidad.

MP3: La presión de diversos medios puede suponer la anulación de las dimensiones anteriores de las personas.

Aparentemente nos encontramos con un texto de carácter neutro, con unas líneas temáticas bien fijadas en un esquema organizativo claro, tal y como se aprecia en la disposición macroestructural (a este hecho hay que añadir los recursos tipográficos que ayudan también a la organización discursiva). Los mecanismos de cohesión gramatical basan su funcionamiento en favorecer la progresión textual atendiendo a dos vertientes. Por un lado, con respecto a las referencias fuera del marco discursivo, sólo se aprecia una serie de marcas de deixis personal en la medida en que el autor incluye a todos los individuos como personas o seres humanos diferenciados unos de otros. Estas marcas se limitan al uso de pronombres posesivos y personales de primera persona del plural (cada uno de nosotros, nos diferencian, nuestros semejantes). El texto pretende estar anclado en unas coordenadas neutras fijadas en un tiempo presente de carácter genérico, de ahí que todos los morfemas verbales se inserten en el presente de indicativo. Por otro lado, con respecto a las referencias incluidas dentro del discurso, únicamente destacan algunos usos anafóricos mediante el clítico lo (en los cuatro guiones) o el uso del posesivo su, remitiendo directamente al ser humano, único protagonista del texto (la apertura, que lo lleva... ; y a anular su propia individualidad y personalidad).

La cohesión léxica cumple un papel fundamental en la creación de los tejidos semánticos de este breve texto. La dualidad persona - ser humano conforma el eje vertebral del discurso, y de ahí surge su repetición y sus continuas referencias a partir de un cargado aparato sinonímico, tal y como se apreciará a continuación. Sin embargo, antes de nombrar el conjunto de sinónimos que aparecen en el texto, hay que tener en cuenta un aspecto reseñable: la nominalización. Ya en el primer párrafo se nos avisa que el individuo posee una serie de cualidades propias y singulares que los diferencian unos a otros. Dichas cualidades calificadas con un par de sinónimos interrelacionados conforman la MP2, es decir, el conjunto de dimensiones que conforma al ser humano 
como único y distinto, volviendo de nuevo a la dualidad sinonímica. Es aquí cuando entra en juego la nominalización deadjetival y deverbal: el autor enfatiza las cualidades de la persona como acciones, como hechos actantes y desencadenantes de las diversas características del individuo, establecidas mediante relaciones sinonímicas y colocaciones léxicas. A través del siguiente esquema se podrá apreciar el esqueleto argumental que define al ser humano como persona, tal y como se afirma en el título del texto analizado:

\section{MP1: SER HUMANO $\rightarrow$ PERSONA $\rightarrow$ CUALIDADES (propias $y$ singulares)}

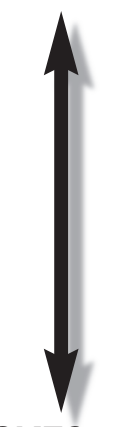

MP2: CUALIDADES $\rightarrow$ DIMENSIONES $\rightarrow$ ser humano como único y distinto.

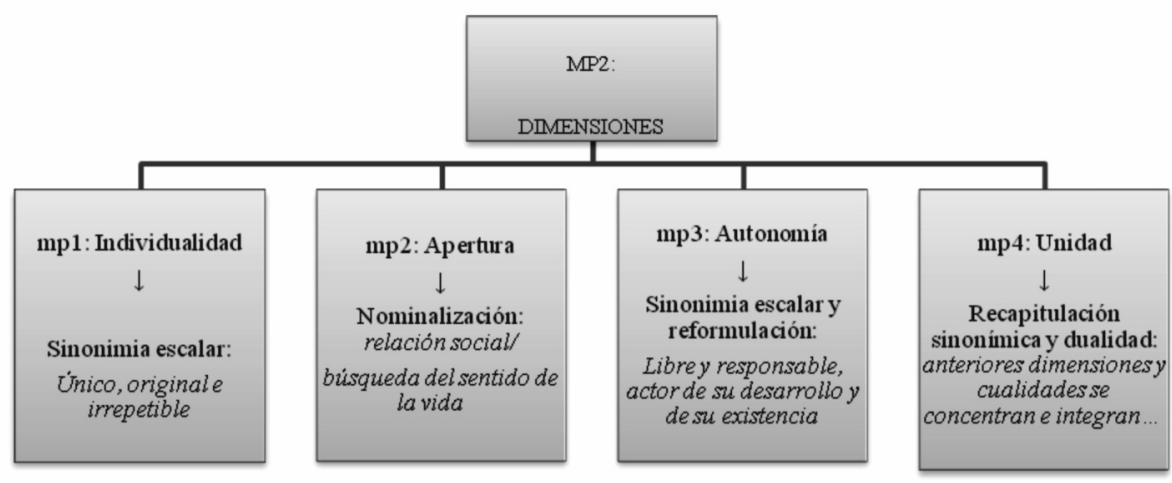

Vemos una clara intencionalidad en el discurso: focalizar la atención en los hechos como actantes, como entidades que realizan la acción de fundamentar al ser humano como un individuo propio y distinguible de otros. El autor no utiliza construcciones como "el ser humano es individual" o "la persona resulta un ser autónomo", sino que mediante las correspondientes nominalizaciones resultantes de las cuatro dimensiones de la persona se enfatiza el conjunto de cualidades de la misma, actuando éstas como cuatro campos 
semánticos propios, incluso como cuatro hiperónimos contextuales que engloban una serie de hipónimos convertidos en mecanismos de relación léxica, fundamentados básicamente en relaciones de sinonimia y semejanza semántica, tal y como apreciamos en el esquema anterior.

El peso de la nominalización es visible incluso en el párrafo final que conforma la MP4, donde se enfatiza que "la presión" de diversos medios puede anular las dimensiones del ser humano anteriormente comentadas, resumidas en la individualidad y personalidad (sería un ejemplo de elipsis cohesiva donde el rasgo "personalidad" englobaría la apertura, la autonomía y la unidad, descargando así de redundancia al texto). Como vemos, no importa el papel de los medios de comunicación, el grupo o los agentes sociales (de hecho, no se nombran más medios) sino la función que realizan, es decir, la presión o el condicionamiento que pueden ejercer al ser humano. La conclusión básica es que la intencionalidad del autor permite construir el texto mediante el énfasis de las acciones en lugar del ser humano como realizador de ellas; se insiste en las características de éste pero no se reincide en él como actante sino como ente que recibe multitud de rasgos definitorios que lo configuran.

Por último, dentro de las relaciones pragmáticas que pueden establecerse en el texto, destaco lo que a mi modo de ver es la metáfora conceptual que vertebra gran parte del discurso: EL SER HUMANO (LA PERSONA) ES UNA MÁQUINA. El individuo, tal y como es descrito en el texto, se conforma y actúa igual que un aparato, se diferencia de otros artilugios por sus acciones y rasgos, responde a una serie de características que lo ponen en funcionamiento y, del mismo modo, está expuesto a un conjunto de hechos que pueden dañarlo o estropearlo. Los usos verbales unidos al contexto discursivo evidencian sobre todo este tipo de relación tropológica. A modo de conclusión, véanse los siguientes fragmentos que fundamentan dicha metáfora conceptual:

1) cada ser humano es un ser único y distinto, configurado por varias dimensiones.

2) la individualidad, que lo convierte en único...

3) la apertura, que lo lleva a la relación social y lo predispone a la búsqueda...

4) la presión de los medios [...] tiende a uniformizar a las personas y a anular su propia individualidad y personalidad. 


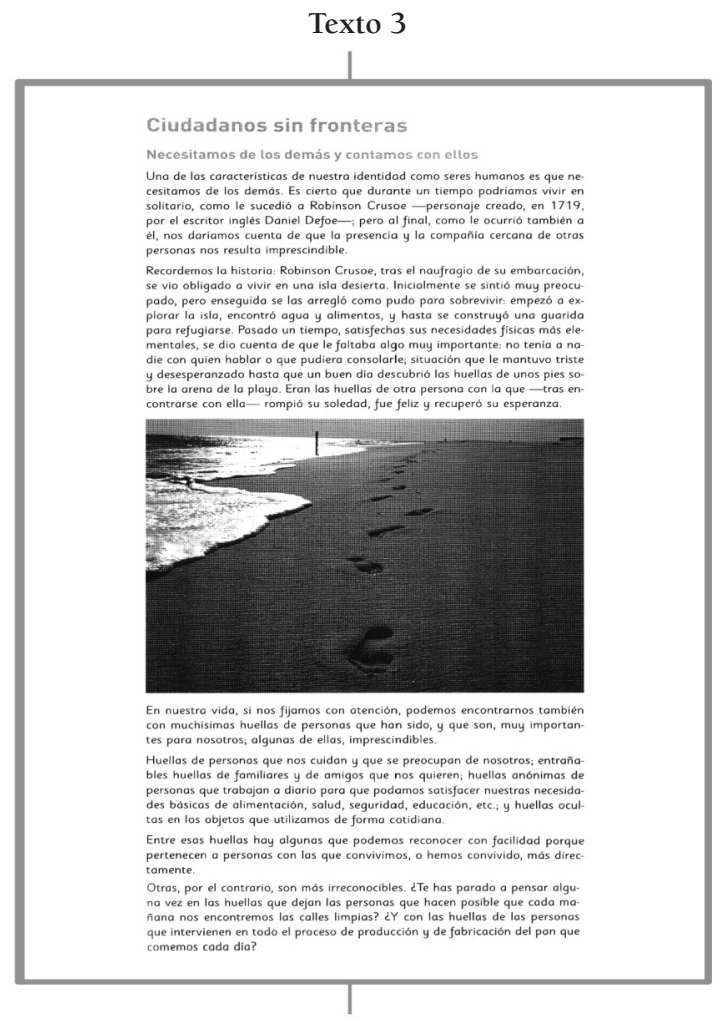

TÓPICO: Los seres humanos necesitamos de los demás.

MP1: Como Robinson Crusoe, las personas podrían vivir solas, hasta que se diesen cuenta de la necesidad de compañía de otras personas.

mpl: Crusoe tuvo que vivir solo tras su naufragio.

mp2: Sobrevivió de diversas formas: explorando la isla, encontrando víveres y construyéndose un refugio.

mp3: Con el paso del tiempo se dio cuenta de que la compañía de otros seres humanos era imprescindible en su vida.

mp4: Tras descubrir las huellas de otra persona y encontrarse con ella, dejó de sentirse solo y fue feliz.

MP2: Las huellas de personas a lo largo de la vida.

mp5: Huellas de personas que nos cuidan.

mp6: Huellas de familiares que nos quieren.

mp7: Huellas de personas que trabajan para satisfacer nuestras necesidades básicas.

mp8: Huellas en los objetos que se utilizan cotidianamente. 
mp9: Huellas que reconocemos fácilmente por la proximidad de sus dueños.

mp10: Huellas como las de las personas que se encargan de la limpieza de las calles o de la fabricación del pan.

El título del texto se basa en la metáfora conceptual LA PERSONA ES UN PAÍS. De ahí la valoración de los ciudadanos sin fronteras junto a la aclaración posterior, es decir, la necesidad de las personas de contactar y mantener relaciones con otros individuos. El autor participa de esta opinión y se incluye a lo largo de todo el discurso; por lo tanto, la deixis personal como referencia exofórica será vital con la aparición casi continua de morfemas verbales de primera persona y pronombres sobre todo de carácter posesivo, tal y como se presenta en la primera oración que constituye el tópico general del discurso: una de las características de nuestra identidad como seres humanos es que necesitamos de los demás. Esta última expresión cuantificativa, los demás, posee su identidad referencial al final del párrafo: la presencia y la compañía cercana de otras personas nos resulta imprescindible. Este hecho de carácter catafórico dota de gran fuerza cohesiva al texto, y reincide en la idea de la necesidad de relación con otros individuos en la comunidad. En definitiva, el aparato deíctico personal señala quiénes son los referentes básicos que no forman parte del marco intertextual pero sí establecen su anclaje enunciativo.

Los hablantes son capaces de conectar los conceptos visibles en la progresión de un discurso gracias al conocimiento del mundo que comparten entre ellos; el autor se aprovecha de este hecho para introducir la historia literaria de Robinson Crusoe como argumento de autoridad y ejemplificativo del tópico que defiende en su discurso. Esta parte del texto conforma la primera gran macroproposición (MP1); aunque la cantidad de conocimiento compartido puede ser algo previo al intercambio, el discurso vuelve a refrescar la memoria del receptor con una breve síntesis del suceso acaecido en la obra literaria. En este segundo párrafo podemos hablar de una anáfora pragmática global, donde los interlocutores pueden crear las expectativas de lo que se va a narrar en el discurso, asociando casi involuntariamente las unidades correferenciales que aparecen de forma progresiva. Éste es el listado de los diferentes recursos:

1) Colocaciones léxicas: naufragio, embarcación, isla desierta; sobrevivir, encontró, construyó, (se las) arregló, refugiarse; isla, agua, alimentos, guarida.

2) Cuasi sinonimia adjetival: obligado, preocupado, triste, desesperanzado.

3) Anáfora simple mediante el clítico "le" (no tenía a nadie con quien hablar o que pudiera consolarle; situación que le mantuvo triste) o utilizando pronombres personales (huellas de otra persona con la que-tras encontrarse con ella).

4) Metáforas conceptuales como LOS SENTIMIENTOS SON OBJETOS (rompió su soledad, fue feliz y recuperó su esperanza). 
Las "huellas" de esa persona "salvadora" de Robinson Crusoe van a conformar el pilar central de la segunda macroproposición del texto, cuya fuerza cohesiva se basa en la repetición total de un mismo lexema junto a una serie de mecanismos que lo acompañan conformando así una estructura coherente desde el punto de vista semántico. Véase el tercer párrafo: En nuestra vida, si nos fijamos con atención, podemos encontrarnos también con muchísimas huellas de personas que han sido, y que son, muy importantes para nosotros; algunas de ellas, imprescindibles. El adverbio también se refiere anafóricamente a la historia del personaje literario anterior y, del mismo modo, introduce esas huellas que son importantes en la vida del ser humano, y que conforman la red cohesiva fundamental hasta el final del discurso. Según la RAE, "huella" es la "señal que deja el pie del hombre o del animal en la tierra por donde pasa". El autor utiliza metafóricamente este vocablo aplicándolo a un dominio destino basado en las acciones e influencias del ser humano a otros individuos cercanos o no. Por lo tanto, la metáfora conceptual será LAS ACCIONES/RESULTADOS SON HUELLAS, creándose así el eje fundamental del discurso hasta su final. A partir de ahí, el autor describe a ese conjunto de personas que nos ayudan en nuestra vida cotidiana, destacando como actante fundamental a estas huellas que, como apreciamos en el siguiente párrafo, aparecen siempre en el inicio de frase, focalizando así su importancia. Éste sería el esquema fundamental:

\begin{tabular}{l|l}
\hline HUELLAS & IDENTIDAD REFERENCIAL \\
\hline 1) Huellas & $\begin{array}{l}\text { Personas que nos cuidan y que se preocupan de nosotros } \\
\text { (colocación cuidar-preocupar) }\end{array}$ \\
\hline 2) Entrañables huellas & Familiares y amigos (colocación léxica) que nos quieren \\
\hline 3) Huellas anónimas & $\begin{array}{l}\text { Personas que trabajan para satisfacer nuestras } \\
\text { necesidades básicas } \\
\text { * Hipónimos: alimentación, salud, seguridad, } \\
\text { educación. }\end{array}$ \\
\hline 4) Huellas ocultas & $\begin{array}{l}\text { En los objetos que utilizamos de forma cotidiana } \\
\text { (elipsis de la identidad personas) }\end{array}$ \\
\hline
\end{tabular}

Resulta curioso cómo el autor del texto construye las diversas frases del párrafo que en sí forma una única oración global. Además de que el concepto "huellas" permanece tematizado al inicio de cada sentencia, es interesante el valor a veces catafórico (desde un punto de vista pragmático) de los adjetivos 
que aparecen junto al vocablo. Por ejemplo, es normal que las "entrañables huellas" sean asociadas a los familiares y amigos; las "huellas anónimas" corresponden a "personas", sin ningún tipo de determinación, que ejercen empleos de la vida cotidiana; por último, las "huellas ocultas" evidentemente ocultan el concepto, tanto que se sustituyen a las personas para dar el papel principal a los objetos que se usan en el día a día.

A modo de conclusión, el autor finaliza el discurso recapitulando con el demostrativo "esas" junto a las famosas huellas que existen dos tipos en la taxonomía que hemos especificado con anterioridad (en un proceso antonímico evidente). Por un lado, las huellas de la gente cercana y, evidentemente, las más fáciles de reconocer; por otro, las que denomina irreconocibles y refiriéndose a ellas mediante el pronombre otras junto al marcador digresor por el contrario. Esto da pie al autor para lanzar dos preguntas directas al lector, utilizando marcas de deixis personal fijando el eje "yo/tú" de una manera literal (ite has parado a pensar alguna vez...?) Se pretende que el lector realice sus propias conclusiones y reflexione sobre las acciones de personas que no conoce pero de las cuales se beneficia, resaltando dos hechos tan cotidianos (y fijados mediante locuciones ancladas en una deixis temporal actual como cada mañana o cada día) como son la función de los colectivos que se encargan de mantener limpias las calles o de elaborar un alimento tan básico como es el pan.

El rasgo fundamental que es necesario extraer de este texto con respecto a los dos anteriores de la misma temática o tópico es la intencionalidad del autor. Mientras que en Pearson-Alhambra o en Edebé se focalizaba la atención hacia la persona, su individualidad, su papel en la sociedad o su autonomía, en este caso nos encontramos con un discurso mucho más retórico, con empleo de técnicas estilísticas propias de la lírica o de la narrativa, para explicar la importancia del ser humano como entidad creada y fundamentada a partir de otros individuos, de otras personas cuyas huellas enriquecen y fortalecen al individuo dotándolo de una serie de servicios y beneficios imprescindibles para el desarrollo de su vida cotidiana.

\section{Resultados}

Una vez realizados los análisis semióticos de los procedimientos cohesivos visibles en el conjunto textual propuesto de la materia Educación para la Ciudadanía, establecemos las siguientes conclusiones que engloban los recursos de cohesión textual más relevantes atendiendo a la línea temática correspondiente a "la persona": 


\begin{tabular}{|c|c|c|}
\hline $\begin{array}{c}\text { Texto } 1 \\
\text { Pearson-Alhambra }\end{array}$ & $\begin{array}{l}\text { Texto } 2 \\
\text { Edebé }\end{array}$ & $\begin{array}{l}\text { Texto } 3 \\
\text { Edelvives }\end{array}$ \\
\hline $\begin{array}{c}\text {-Gran aparato deíctico } \\
\text { personal (sentimos, } \\
\text { tenemos, eres). } \\
\text {-Repetición léxica total } \\
\text { (persona) y mecanismos } \\
\text { de sustitución como la } \\
\text { sinonimia (persona, ser } \\
\text { humano, ser social) o la } \\
\text { hiperonimia } \\
\text { (sentimientos, razón, } \\
\text { dignidad). }\end{array}$ & $\begin{array}{c}\text {-Nominalizaciones y } \\
\text { casos de sinonimia } \\
\text { (individualidad, apertura, } \\
\text { presión; único, original, } \\
\text { irrepetible). } \\
\\
\text {-Metaforización LA } \\
\text { PERSONA ES UNA } \\
\text { MÁQUINA (ser humano } \\
\text { configurado por varias } \\
\text { dimensiones). }\end{array}$ & $\begin{array}{c}\text {-Amplia metaforización } \\
\text { (LA PERSONA ES } \\
\text { UN PAÍS; } \\
\text { LOS SENTIMIENTOS } \\
\text { SON OBJETOS.) } \\
\text {-Recursos como la cuasi } \\
\text { sinonimia (obligado, } \\
\text { preocupado) o las } \\
\text { colocaciones léxicas } \\
\text { (naufragio, isla desierta). } \\
\text {-Repetición léxica total } \\
\text { en estructuras } \\
\text { paralelísticas (las huellas } \\
\text { como las acciones o } \\
\text { resultados del ser } \\
\text { humano) } \\
\text {-Procesos retóricos como } \\
\text { la antonimia en } \\
\text { interrogaciones de } \\
\text { carácter retórico. }\end{array}$ \\
\hline
\end{tabular}

Por último, a modo de conclusión general, propongo las siguientes reflexiones generales sobre cada uno de los manuales (nombrados mediante su editorial) derivadas del análisis de sus textos y la relevancia en ellos de los procedimientos cohesivos desde la perspectiva semiótica, y atendiendo a la línea temática general establecida.

- Pearson-Alhambra (texto 1): ofrece una caracterización del individuo como un ser puramente racional que se distingue del colectivo animal, calificándolo como una entidad humana, social, digna y perteneciente a una sociedad.

- Edebé (texto 2): visión neutra del individuo que se configura casi como una máquina, respondiendo a una serie de dimensiones o rasgos que pueden formarlo como ser social o pueden dañarlo. 
- Edelvives (texto 3): tratamiento discursivo desde una vertiente puramente literaria y preciosista donde el individuo se forjará gracias a otros individuos que lo ayudarán, cuyas huellas en la vida servirán para conformar las huellas del primero, desembocando así en la cadena social.

\section{Conclusiones}

El lenguaje, como actividad o instrumento de interacción social, posee una función primordial: la comunicación. Por lo tanto, su estudio debe entenderse como una actuación recíproca entre emisor y receptor dentro de un contexto de uso determinado. Si partimos de esta premisa fundamental, es necesario tener en cuenta que tradicionalmente las gramáticas del español han realizado sus estudios desde un paradigma puramente formal, es decir, adoptando una postura descriptiva e inmanentista que configura una versión normativa y estándar de la lengua. Sin embargo, el análisis exclusivamente lingüístico y formal no constituye un estudio completo y satisfactorio del lenguaje; frente a dicha cuestión aparece el paradigma sistémico funcional cuyo objetivo es la necesidad de evidenciar una explicación de la producción lingüística unida a factores sociales, discursivos y pragmáticos. Desde este precepto o punto de partida surge este trabajo cuyo objetivo primordial es el tratamiento, desde una perspectiva semiótica, de los mecanismos de cohesión textual mediante análisis discursivos circunscritos a textos del ámbito académico y, concretamente, a un corpus proveniente de manuales pertenecientes a la asignatura Educación para la Ciudadanía y los Derechos Humanos. A modo de recordatorio, sabemos que la cohesión textual está íntimamente relacionada con los significados ideacionales/experienciales del texto, es decir, con el establecimiento del campo o ámbito temático discursivo. Para ello, nuestro primer paso a la hora de analizar los diversos discursos del corpus propuesto ha sido establecer la organización particular de cada texto, es decir, las denominadas macroestructuras. Este hecho se justifica ya que los procedimientos de cohesión textual mantienen una relación evidente con los significados textuales que se concentran en la organización informativa del texto. Además, esta organización permanece a su vez condicionada por el género que, en este caso, corresponde al educativo o académico con los manuales o libros de texto, cuyo prototipo de discurso es el texto explicativo. Partiendo de esta base, esta investigación pretende ofrecer una descripción detallada del uso de los procedimientos lingüísticos de cohesión en el discurso y su función semiótica, además de la estructuración informativa que conllevan en el discurso; asimismo, este propósito ha ratificado la utilidad necesaria de los mecanismos de cohesión textual ya que, mediante su uso, se puede tratar cómo se construye el contexto, qué 
datos se aportan sobre él y cuáles son los valores o preceptos ideológicos que se pretenden transmitir, partiendo en este caso de una temática general de carácter social como es "la persona" insertada en los contenidos de la materia Educación para la ciudadanía.

La identificación, la enumeración y el análisis exhaustivo de los mecanismos de cohesión textual (recursos de carácter gramatical o léxico y procedimientos de conexión) junto a su interacción en el discurso han intentado aportar a la investigación de la pragmática y el análisis del discurso dos aspectos fundamentales: por un lado, partiendo de la lingüística sistémico funcional, la comprensión del concepto "texto" en un marco donde se une lo semántico y lingüístico desde una perspectiva pragmática y contextual; por otro, la fijación del análisis discursivo como un continuum donde entran en juego la información contextual, la organización del significado, la estructuración pragmática y la fijación lingüística del texto. Además, se han evidenciado las relaciones lógicas entre estructura textual y cohesión, es decir, entre significados ideacionales y textuales. Resulta evidente que cualquier texto debe poseer un contenido informativo intencionalmente decidido y organizado por el hablante que desea comunicar un hecho concreto. Por lo tanto, es fundamental tener en cuenta cuál es la organización que se ha configurado en el discurso, con el fin de ponerla en relación directa con los recursos cohesivos utilizados y que han ayudado a fijar ese esqueleto significativo, consiguiendo así un modelo de análisis completo en el cual se aprecie la unión entre cohesión textual y coherencia semántica. Por último, considero que la aportación más relevante de este proyecto es evidenciar el sistema de opciones de la lengua, es decir, los diversos significados que se pueden plantear en un tema único como es "la persona" $y$, en definitiva, las muy diferentes maneras de presentar la información dentro de un mismo género discursivo, el "libro de texto", cuyo tipo de texto prototípico es el explicativo.

\section{Referencias bibliográficas}

Aguilar, T., Caballero, A., Dausà, N., Mestre, J. y Vilaseca, S. (2007): Educación para la ciudadanía y los derechos humanos (ESO). Barcelona, Grupo Edebé.

Anaut, L. (2002): Valores escolares y educación para la ciudadanía. Barcelona, Graó. BOE (Boletín Oficial del Estado) 106 de 4 de mayo de 2006.

Bolívar, A. (2007): Educación para la ciudadanía. Algo más que una asignatura. Barcelona, Graó.

CREA: Corpus de referencia del español actual. Madrid, Real Academia Española.

Dijk, T. A. van (1978): La ciencia del texto. Barcelona, Paidós, 1983.

Eggins, S. (2002): Introducción a la lingüística sistémica. Logroño, Universidad de la Rioja. Traducción, prólogo y glosario de F. Alcántara. 
Eggins, S. \& J. R. Martin (2003): "El contexto como género: una perspectiva lingüística funcional", Revista Signos, v.36, 54, Valparaíso.

Ghio, E. \& M. D. Fernández (2008): Lingüística Sistémico Funcional. Aplicaciones a la Lengua española. Santa Fe (Universidad Nacional del Litoral), Waldhuter Editores.

González, F. (2007): Educación para la Ciudadanía y los Derechos Humanos. Proyecto más que uno. Madrid, Edelvives.

Halliday, M. \& R. Hasan (1989): Language, context, and text: aspects of language in a social-semiotic perspective. Oxford, Oxford University Press.

Halliday, M. (1978): Language as a Social semiotic: the social interpretation of language and meaning. London, Edward Arnold.

Halliday, M. (1985): An Introduction to Functional Grammar. London, Edward Arnold. Halliday, M. (1997): Cohesion in English. London, Longman.

Hassan, R. \& G. Perrert (1994): "Learning to function with the other tongue". En T. Odlin (ed.), Perspectives on pedagogic grammars. New York, Cambridge University Press.

Lyons, J. (1997): Semántica lingüística: una introducción. Barcelona, Paidós.

Marimón, C. (2008): Análisis de textos en español. Teoría y práctica. Alicante, Publicaciones de la Universidad de Alicante.

Martín Zorraquino, M. A. y J. Portolés Lázaro (1999): "Los marcadores del discurso". En I. BOSQUE y V. DEMONTE (comps.): Gramática descriptiva de la lengua española. Madrid, Espasa Calpe, págs. 4051-4213.

Mederos Martín, H. (1988): Procedimientos de cohesión en el español actual. Santa Cruz de Tenerife, Excmo. Cabildo Insular de Tenerife. 